\title{
INTEGRATED DIGITAL TECHNOLOGIES FOR THE ARCHITECTURAL REHABILITATION \& CONSERVATION OF BEINN BHREAGH HALL \& SURROUNDING SITE, NOVA SCOTIA, CANADA
}

\author{
Percy, K. ${ }^{\text {a }}$, Ward, S. ${ }^{\text {a }}$ Santana Quintero, M. ${ }^{a}$ Morrison, $\mathrm{T}^{\mathrm{b}}$ \\ ${ }^{a}$ Carleton Immersive Media Studio (CIMS), 1125 Colonel by drive, Ottawa, On, K1S 5B6 Canada, kpercy@gmail.com - \\ sarah_l_ward22@hotmail.com -Mario.santana@carleton.ca \\ ${ }^{\mathrm{b}}$ Heritage Standing, Fredericton, Canada.
}

Commission VI, WG VI/4

KEY WORDS: 3D Scanning, 3D imaging, Recording, Photogrammetry, EDM, Computer-Aided Drawing, Conservation, Alexander Graham Bell, conservation, UAV, Building Information Modelling (BIM), energy simulation, Documentation

\begin{abstract}
This contribution summarizes the collaboration between Carleton Immersive Media Studio (CIMS) and Heritage Standing in the use of digital technologies to document the Beinn Bhreagh Hall historic site (house and immediate surroundings) in Baddeck, Nova Scotia for its rehabilitation and protection. The project objectives were to develop a prototype for research and training using 3D scanning, and Building Information Modelling (BIM), as well as other emerging surveying tools to understand the state of conservation of Historic Places in Canada, providing relevant and appropriate information for their rehabilitation and maintenance. The vehicle of this research was the documentation and modelling of this important landmark, the summer home of Dr. Alexander Graham Bell in Victoria County, Nova Scotia. This unique 19thC building, currently under review for designated as a national historic site.
\end{abstract}

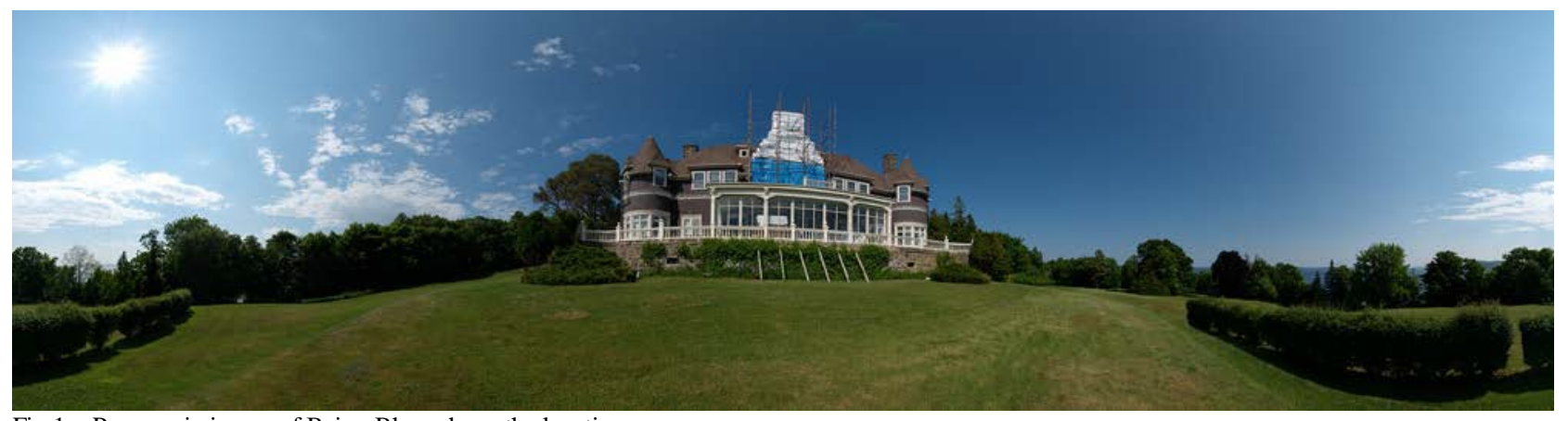

Fig.1 - Panoramic image of Beinn Bhreagh south elevation

\section{INTRODUCTION}

The recording of historic places requires an accurate reproduction of the subject and its context. These statements have been already ascertained in particular from the very essence of heritage conservation charters, as for Article 2 on the Venice Charter (1964), which states, "the conservation and restoration of monuments must have recourse to all the sciences and techniques, which can contribute to the study and safeguarding of the architectural heritage.”

Furthermore, it is stated in Article 16 that "in all works of preservation, restoration or excavation, there should always be precise documentation in the form of analytical and critical reports, illustrated with drawings and photographs. Every stage of the work of clearing, consolidation, rearrangement and integration, as well as technical and formal features identified during the course of the work, should be included. This record should be placed in the archives of a public institution and made available to research workers. It is recommended that the report should be published” (Venice Charter, 1964).

'Precise documentation' in conservation works deals with applying techniques that can accurately acquire the building's context, geometry and texture, as well as features.

The 'analytical and critical report' deals with the production of assessments regarding the actual condition of the subject, especially ensuring an adequate quality of the measured dataset of geometric and texture for thematic mapping.

The Canadian Standards and Guidelines for the Conservation of Historic Places considers that "Understanding an historic place is an essential first step to good conservation practice", and "it is normally achieved through research and investigation". It additionally states that "the information collected in this phase will be used throughout the conservation decision-making process and should remain accessible" (Canada Historic Places, 2010).

Therefore, appropriate decisions in heritage conservation are based on timely, relevant and accurate information regarding the conditions, materials and evolution of heritage buildings and landscapes. As such, the process of documenting, recording and analyzing heritage places is an essential part of their conservation and management.

Heritage information plays an essential role in the adequate preparation, implementation and monitoring of conservation strategies. For this reason, the acquisition and management of information is important for the understanding of cultural heritage. Digital technologies have revolutionized the speed and completeness in recording heritage places; these techniques offer a myriad of new opportunities for collecting, analyzing and disseminating information about heritage sites. With these new opportunities, there are also conflicts, and an intense effort 
to build digital media into the education of conservation professionals.

Given the significance of the Beinn Bhreagh property, at the request of Sara Grosvenor and Heritage Standing and support from Mitacs, the Carleton Immersive Media Studio (CIMS) at Carleton University prepared a reliable and accurate digital baseline record for the house and immediate surroundings. This baseline record consists of a photographic portfolio of the property, conventional measured drawings (eg. plans, elevations and cross sections) and a three-dimensional Building Information Modeling (BIM). The resulting BIM model was used for running emerging 3D techniques for evaluating the structural integrity and inherent sustainability of the building.

\subsection{Scope of work}

According to David A. Watt, when surveying, "respect of a building or monument needs to be qualified with a suitable adjective. The principal methods of survey are” (Watt, 2010):

- Measured surveys of buildings to provide drawings of their layout.

- Evaluation surveys for acquisition, compensation, disposal, investment, insurance or taxation.

- Building surveys of the structure and fabric of properties to assess their condition and prepare reports, schedules of condition, schedules of dilapidations or specifications for programs of maintenance and repair;

- Archaeological surveys of the material remains of earlier societies including archaeological deposits below ground, ruins, and standing structures.

This contribution deals with the preparation of a measured survey to serve as baseline information for other assessments, such as building and archaeological surveys that would reveal the current state of conservation by a formal inspection of the significance, character defining elements, integrity of materials, defects, damages and/or decay.

\subsection{Site History \& Significance}

The Beinn Bhreagh site, located in Baddeck, Nova Scotia, is significant to Canadian, American and Universal heritage as it was inhabited by and inspired the genius of Alexander Graham Bell. His wife, Mabel Hubbard Bell, not only assisted in her husband's accomplishments through her wisdom and successes but also contributed substantially to the community of Baddeck. As such, their house, Beinn Bhreagh Hall, also referred to as "The Point" and surrounding grounds are seeking Canadian Federal Heritage Designation in her name.

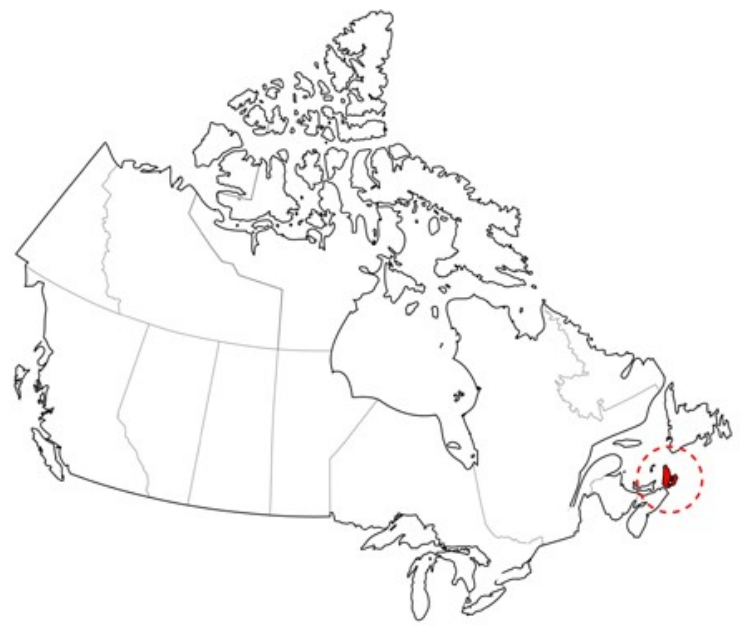

Fig.2 - Beinn Bhreagh at Baddeck, Nova Scotia, Canada

In 1885, Alex and Mabel Bell travelled to the Canadian East Coast, where Bell decided build a permanent residence on a 22acre site in Baddeck Nova Scotia. He chose the name Beinn Bhreagh, meaning Beautiful Mountain in Gaelic, as a means of celebrating the site's resemblance to Scottish hills. Located at the point of the Red Hill Peninsula Beinn Bhreagh Hall has extensive views of the Bras D’Or Lakes and Baddeck.

Completed in 1893, the building is a frame, modified Queen Anne-style structure with massive limestone and brick chimneys. American architect Arthur Greene Everett designed the home, with extensive influence by both Alec and Mabel.

The Nova Scotia firm Rhodes Curry Company constructed the building between 1891 and 1893, using all local materials. The home showcases Bell's attention to detail and innovative mind through elements such as the wood detailing in the great hall, the 11 fireplaces throughout the main and servants wing, as well as innovative forced air and passive ventilation systems. The site itself accommodated Bell's inventive genius and love of leisure.

Beinn Bhreagh Hall includes a landscaped garden, planned primarily by Mabel, which is rich in botanical history and diversity. The gardens naturally flourish due to a micro-climate ideal for exotic trees and fruits. Alexander and Mabel Bell and their daughters Elsie and Daisy spent most of their years here between 1893 and 1923. The house retains its heritage value from this period of Mabel Hubbard Bell's residency.

\section{RECORDING BEINN BHREAGH FOR POSTERITY}

\subsection{Selected toolbox: metric survey equipment}

In close collaboration with Heritage Standing, the CIMS team employed consolidated and emerging surveying equipment to capture the shape, color and geometric configuration of Beinn Bhreagh Hall and immediate surroundings for its rehabilitation and conservation.

The selected toolbox consisted of dimensional and visual tools for capturing the scale and orientation of the building elements, as well as its topography. These included. 
- Leica Geosystems Total Station TS11, with a distance accuracy of $2 \mathrm{~mm}$ and angular $2 \mathrm{ppm}$ (Leica Viva TS11 Datasheet, 2010)

- Leica Geosystems 3D scanning device, model C10 with a point to point accuracy of $6 \mathrm{~mm}$ position and 4 mm distance (Leica ScanStation C10 DS, 2011)

- Digital Photogrammetry using high-resolution Nikon D800 DSLR camera with 36 MP (Nikon D800, 2014) and a DJI Phantom 2 Vision, which is a low cost Unmanned Aerial Vehicle (UAV) (Phantom 2 Vision Specs, 2015)

Furthermore, in order to obtain record and panoramic photography for capturing architectural, condition and character defining views (and details) images were captured using the high-resolution Nikon D800 DSLR camera with 36 MP (Nikon D800, 2014) and a Nikon D300 DSLR with 12 MP. For panoramic photography a Nodal Ninja adapter was used. Additionally giga pixels images were generated using a Gigapan adapter and software.

\subsection{Recording approach}

The measured drawings and other deliverables were produced using different recording tools in order to maximize the documentation of the site given the onsite and office timeframe available.

The fieldwork consisted of 17 days of on-site recording in two separate missions (June-July and September 2014), primarily using the previously described direct and indirect surveying techniques. The compilation of the baseline record of Beinn Bhreagh Hall was implemented through the following steps:

- Establishment of a surveying network

- Recording the building: exterior and interior

- Site boundary and buffer zone

- Site Photographic portfolio

- Post recording production: two-dimensional drawing (CAD), BIM modelling

- Structural and sustainability performance audit

Upon returning to Ottawa, the team processed the collected information using Computer-Aided Drafting, Building Information Modelling and image processing applications for the preparation of the requested deliverables.

The deliverables, such the Building Information Modelling (BIM) models were further used in structural and sustainability simulations.

\subsection{Surveying network: Setting up a reliable coordinate system}

The TS11 Total station was used to geometrically link the 3D scanning, photogrammetric record and the survey of the individual spaces (plans, elevations and sections).

This Total Station is an Electronic Distance Measurement (EDM) tool, that after being properly levelled in a fix measuring point and orientated using a base bearing from a second measuring post (bench-mark or standpoint) records measured points by projecting an infrared beam (EDM mode) to a prism rod (reflector), or a laser beam to a surface up to 80-300 $\mathrm{m}$ from its position (REDM mode). This action calculates threedimensional co-ordinates, and if required, other geodetic information between the point and the original reference point, such as angles, distances, different of heights.

For this reason, this instrument was used to survey a network of fixed points from the interior and exterior perimeter of the house as well as its immediate surroundings. A local coordinate system was created by orientating the survey to magnetic north. As such, a future professional surveyor could attach this network to the National Canadian grid by matching selected base points from the local system to the National network.

The first stage of the survey was to establish an outer ring of control points measured around the house. Secondly, control points were measured using washers painted in red and glued to selected areas around outer elevations of the house with epoxy. Thirdly, photogrammetric controls were measured using inherent features of the house; this prevented unnecessary gluing of targets. Finally, an inner coverage of control points was measured using target stickers. These three networks of points allowed tightening a network of controls to link the different surveying techniques.

\subsection{Recording the Building's envelop and Interior spaces}

A combination of 3D scanning and photogrammetry was used to capture the geometric configuration of the house and its immediate surroundings. As previously explained, the 3D scanning device was used to capture a dense point cloud of the scene being surveyed from different positions. To complete the set of reliable measurements, photogrammetry was used to take elevated photographs in order to capture those elements invisible to the scanner by employing both an Unmanned Aerial Vehicle (UAV) and an Aerial Lift Work Truck. From the photogrammetric models of the roof and elevations it was possible to produce a mesh model and dense point clouds. The resulting point clouds from both techniques were combined in specialized Computer Aided Drafting (CAD) and Building Information Modeling (BIM) software for the processing phase of this documentation project.

\subsection{Site topography}

In order to measure and represent the immediate topography of the terrain, the team proceeded to record the home's immediate surroundings using laser scanning as a way of documenting this important landmark's location and orientation.

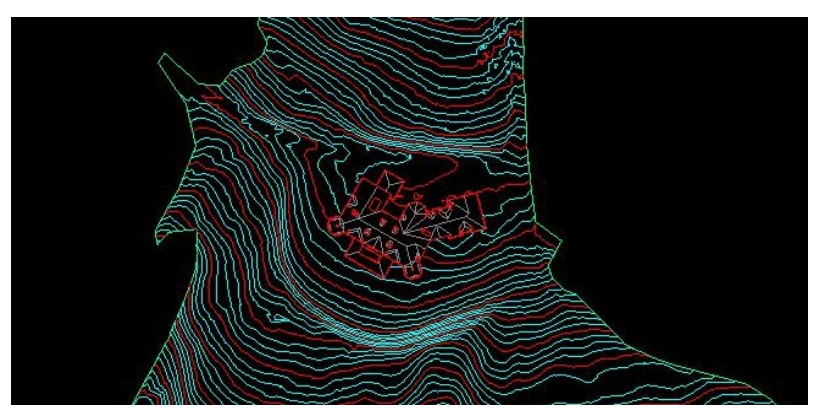

Fig.3 - Beinn Bhreagh 3D topography from pointclouds

\subsection{Detailed 3D Scanning}

3D scanning applications produce three-dimensional information in the form of point cloud data. Hundreds or thousands of points are collected from a scanned surface and can be used to create digital drawings or models. Laser scanning 
techniques yield highly accurate data in a relatively short time frame. Each laser-scanning scenario can record a 360-degree environment.

In order to efficiently acquire data from the Beinn Bhreagh Hall site, the project team utilized a "time-of Flight" device which,, according to English Heritage allows users "to survey building façades and interiors, resulting in line drawings (with supporting data) and surface models” (English heritage, 2007).

Furthermore, this type of scanning device acquires measurements by using a "two-way travel time of a pulse of laser energy to calculate a range." As a result, "This type of scanner can be expected to collect many tens of thousands of points every minute by deflecting this laser pulse across the surface of an object, using a rotating mirror or prism“ (English Heritage, 2007).

Böhler and Marbs generically describe a laser scanner as a "device that collects 3D co-ordinates of a given region of an object's surface automatically and in a systematic pattern at a high rate (hundreds or thousands of points per second) achieving the results (ie three-dimensional co-ordinates) in (near) real time.” (Böhler \& Marbs, 2002) Several sets of point cloud data can be merged together from separate scanning exercises if controlled survey points are established. From the combined point cloud data, detailed three-dimensional models can be generated.

A crucial issue in laser scanning historic surfaces is "determining appropriate point density" (English Heritage, 2011) for the correct preparation of measured drawings and 3d models that will reveal geometric information relevant to conservation practices and the desired graphic scale. According to English Heritage, $35 \mathrm{~mm}$ is the optimal resolution interval "for point density required to give $66 \%$ probability that the feature will be visible" (English Heritage, 2011). For this reason the CIMS team conducted the survey using higher resolution intervals to ensure the integrity of the data for the production of the required graphic deliverables where the final resolution selected was $0.05 \mathrm{~m} \times 0.05 \mathrm{~m}$ at $100 \mathrm{~m}$ for exterior spaces, and $0.1 \mathrm{~m} \times 0.1 \mathrm{~m}$ at $100 \mathrm{~m}$ for interior spaces.

\subsection{Aerial and terrestrial photogrammetry}

Photogrammetry can be defined as "the art, science, and technology of obtaining reliable information about physical objects and the environment through the processes of recording, measuring, and interpreting photographic images." (Wolf, Dewitt, \& Wilkinson, 2014). This technique can obtain measurements of objects, buildings, sites or earth surfaces. When images are clear and captured at a high resolution it can be a very accurate technique based on the assumption that photographic images are in perspective as well as generated from a centrally projected system and, therefore, follows geometric and mathematical principles.

It is impossible to define a position in space with only a single image, but using two perspectives or two photographs that are taken from two different points allows for the surrounding spatial conditions to be calculated from the images. When conducted correctly, one should have enough information to assess the spatial position of every single point visible in both images and determine the intersection of the two projective bundles. This technique is comparable to the process of taking measurements with a total station from two different positions.

For the purpose of this project, "multi-image photogrammetry or structure from motion” (McCarthy, 2014) was used, which is an approach produced from recent developments in computer vision that allows us to obtain 3D scenes from 2D images using highly automated workflows. This process was carried out by capturing a sequence of overlapping and oblique images taken from a scene (or subject) at a consistent distance. Recent algorithms use matching features between pairs of photographs in sequences, which along with the information contained in the images (adequate camera motion, overlap and structure scene) uses the camera parameters to calibrate the images. Subsequently, a depth map is created with each pixel contained in the image producing a 3D dense point cloud and/or surface model. The resulting product is a series of consolidated mesh models of important rooms and spaces.

The photographs of the site were captured using a combination of simple tripod images from the ground and a light drone implemented to capture aerial views. This UAV DJI Phantom 2 has a camera with 14 MP Resolution and a Field of view (FOV) of $120 \% 110 \% 85^{\circ}$. The team used HD Recording mode at $1080 / 60 \mathrm{i}$ [11] in order to produce still images from the video to reconstruct the photogrammetric model.

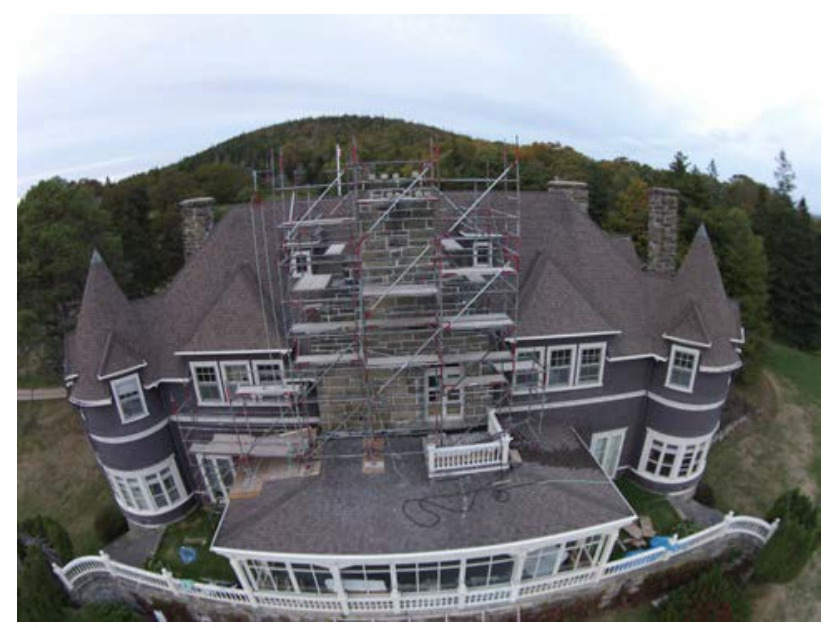

Fig.4 - Roof details captured with the UAV

\subsection{Two-dimensional drawing production}

One of the main project deliverables was a two-dimensional drawing set that would provide an as found record of the site. The production of the two-dimensional drawing set is an amalgamation of data produced from EDM, photogrammetry, $3 \mathrm{D}$ scanning and hand measurements. Initially, the drawings produced from EDM are standardized and improved with hand measurements and photographs. Once these drawings are legible, information from photogrammetric documentation and 3D scanning are imported into Autocad in the form of pointcloud. These pointclouds were clipped and amalgamated within Autocad to produce an overall drawing from the data produced from photogrammetry and $3 \mathrm{D}$ scanning. It is ultimately left to the discretion of the technician to interpret the information from the various pointclouds, orthophotos and EDM data in order to produce accurate drawings.

The integration of the various documentation methods ultimately produced drawings that capture the data required of 
the project as well demonstrates the qualities of each method through the aesthetics seen in the drawings. Each method proves to have advantages, either in terms of overall accuracy or depicting the qualitative nature of the structure. The final product validates that EDM, photogrammetry, 3D scanning and hand measurements are effective in producing overall drawings that demonstrate an accurate representation of the site.

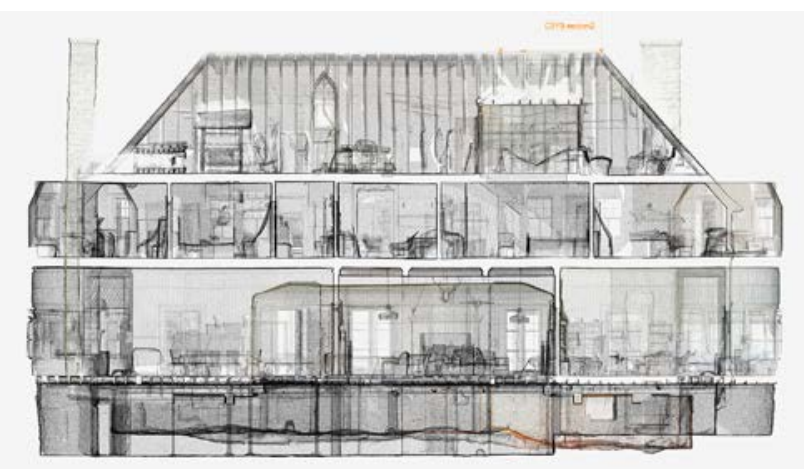

Fig.5 - Section through the pointcloud for drawing in Autocad

\subsection{Record photography to compile a complete portfolio of the house}

Photography is probably the most widely used technique in recording heritage places for inventories. When it is done carefully, it can provide a quick and reliable "as built" condition assessment of any property by capturing its geometry, texture, shape, and colors. Although there are many types of photography, architectural photographs for assessing condition and character defining elements are the most relevant. These photographic records vary in scope from capturing external context views, perspective views and elevations to internal spaces and details of significant elements and conditions.

Conventional architectural photography was employed on site to capture the house and its immediate surroundings. The goal was to systematically record features of the building that were relevant to understanding its condition, character defining elements and other potential issues that illustrate the need for conservation of this important landmark.

Full spherical panoramic photographs were employed at every scan station assisting in capturing the character defining elements of this heritage place. Spherical panoramic photographs employ overlapping photographs to generate a 360 view of a scene.

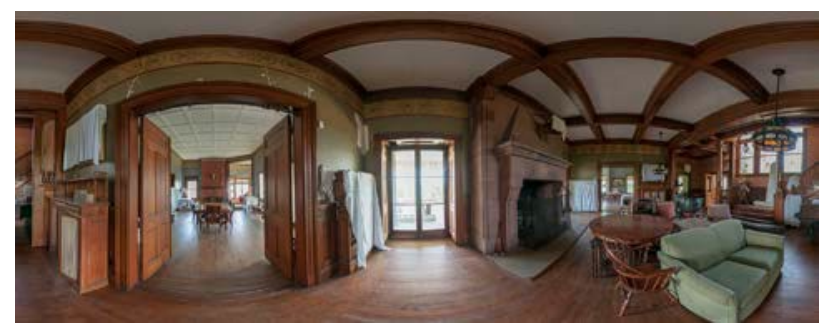

Fig.6 - Full spherical panoramic image of the main hall

The combination of these record photography techniques were used to consolidate an integrated photographic portfolio of the property. This portfolio includes a complete set of views related to the following categories: architectural photography, documentation photography, character defining element photography, and condition photography.

\section{EMERGING APPROACHES USING THE SURVEYED INFORMATION AND BUILDING INFORMATION MODELING TECHNIQUES}

\subsection{Building performance simulation}

Using a simplified version of the BIM model prepared on Beinn Bhreagh, a concise report was prepared that assessed the building performance of the property, which included heating \& cooling load analysis on hourly, weekly, and monthly data.

Moreover, this report included an analysis on infiltration rate, solar radiation, heat addition \& extraction by windows. There were limitations identified in this performance analysis report regarding the simulated model.

First, the weather data used is not the local weather data for the selected site, i.e. wind speed is defined at 10 meters above sea level which makes the wind speed higher than that on site. Additionally, direct and diffuse solar radiation differs from the local weather data.

Furthermore, detailed occupational schedules were not provided, thus an assumption was made based upon ASHRAE default occupied schedules for domestic activities.

Ideal loading was assumed in the HVAC analysis to predict the heating and cooling demands to maintain certain room temperatures. This assumption could unintentionally give high values for heating and cooling loads as the HVAC cycles were assumed to be running continuously.

As previously mentioned, the chosen infiltration rate used approximately 0.7 ach (air change per hour), which is considered high. A high infiltration rate contributes to heat loss from the building, and as such the demand for heating will increase. From the simulation results, it can be observed that heating loads increased by almost $50 \%$ due to high infiltration rate.

In conclusion, this simulation report was meant for building performance analysis and not as a calibrated energy model. Thus, some assumptions were necessary in order to estimate the building performance. As mentioned above, since the building envelope does not contain insulation and the simulation employed clear $3 \mathrm{~mm}$ double glazed windows, ideal HVAC loading from heat loss and infiltration during the winter months is high, resulting in high heat loads.

\subsection{Inherent environmental features of Beinn Bhreagh}

Houses built prior to 1920 tend to have more energy conserving features built into their building envelope and orientation. Beinn Bhreagh Hall exhibits the characteristics of a home built in a northern climate attempting to exploit its inherent environment features. Its orientation appears to have been chosen in order to maximize ventilation, natural light penetration and shading. The immediate vegetation implements shading and reduces heavy winds. The surrounding environment features prescribe the plan arrangement of the home's interior in order to exploit passive energy. Rooms that 
require less light and a cooler environment are placed relative to the north, while those requiring additional ventilation, warmth and daylight are facing south. Additional inherent environmental features exhibited on the exterior of the house include the dark façade to maximize solar heat absorption in the winter months and roof overhangs to control solar heat gains.

Openings play a large role in passive energy control as they regulate light penetration as well as heating/cooling loads. The location and size of the openings of Beinn Bhreagh Hall are typical of homes designed in northern climates. The smaller and limited openings towards the north and the expansive, operable windows to the South provide ventilation and light penetration while reducing heating loads. The basement windows in the stone foundation walls utilize splayed window reveals in order to maximize light penetration while minimizing the size of the opening. In order to control air exchange, the main entrance vestibule and rear sun porch contain double door entrances.

The interior features of the house serve to control heating and loads. The location of the central chimneys assists in distributing heat throughout the house's entirety through the interior-facing thermal masses. The high ceilings in the main interior rooms assist in cooling in the summer.

\subsection{Structural Analysis}

This section examines experimental approaches and methods of analysis for the structural integrity of existing buildings using Autodesk Revit 2014. The chosen approach originates from an architectural heritage documentation perspective with the assistance of Heritage Standing.

Software packages like SAP2000 for structural analysis are specialized tools used in the field, but the focus of this exercise was to examine and extend the potential of tools which are common in architecture but can be employed for structural analysis in certain capacities.

For this assessment the following approach was implemented: first, the point cloud of the area to be modelled for structural analysis was defined; second, specific areas containing the modelled beams and columns were analyzed.

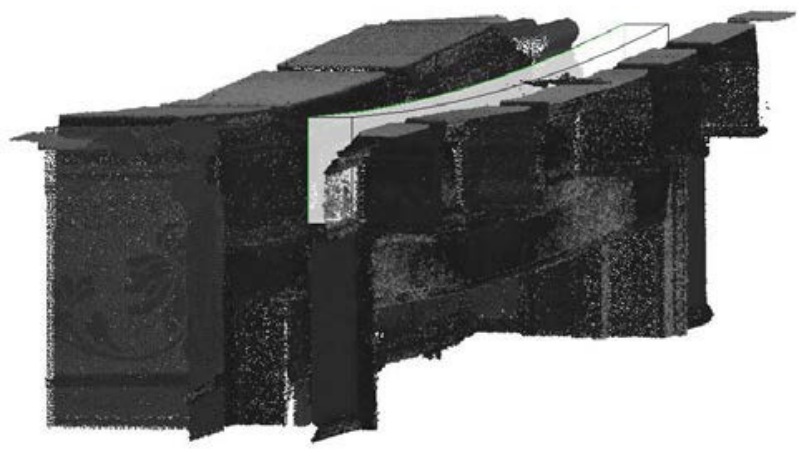

Fig.7 - Beam from the main hall modelled from pointcloud demonstrating structural failure

As a material, Douglas Fir was selected for each part of the assembly because it is the closest modern material that can serve as a conservative comparison to the old growth SPF that is likely in place. Spaced at $305 \mathrm{~mm}$ O.C., a live point load ($1.91 \mathrm{kN}$ ) was applied at each intersection of the floor joists across the top of the beam. At the points where the edge of the wall meets the beam two extra point loads for doubled floor joists have been included.

After a number of models were completed, one of the significant challenges we encountered involved geometrically complex components modelled in place that did not have analytical and physical material properties associated with them. For example, creating an accurate analytical model from the beam in Fig.7 was not possible, thus an analytical model could not be produced from complex, modelled in place families within Revit. A basic model with boundary conditions could be achieved, but they lacked the deformations of the structure.

Other significant challenges we encountered included modelling for the transfer of forces through the floor to the supporting beam. The analytic model does not recognize the transfer of force between a floor and its supporting beam. In order for the forces to pass from the floor joists to the beam and down the columns, point loads had to be placed at the intersection of each floor joist across the beam in place of the modelled floor.

To conclude, the application of these methods has a great deal of potential for analyzing the conditions of existing structures. This study is by no means an exhaustive investigation, but by attempting a basic analysis with this specific case we have opened up new research avenues and hope to expand this knowledge on subsequent projects. As a didactic and collaborative tool, the analytical model generated in Revit has the potential to foster a better understanding between disciplines by using similar tools for diverse uses in engineering and architecture.

While BIM structural modelling appears to have potential, extensive collaboration between the structural engineer and architect involved would be required and was not possible for this research.

\section{CONCLUDING REMARKS}

The application of digital techniques for the recording, visualization and eventual simulation of Beinn Bhreagh Hall demonstrated how these tools can provide relevant and accurate information regarding the site's conservation as well as a posterity record in case of damage or further deterioration.

During the fieldwork and processing phases of the project, the team implemented appropriate applications to deliver adequate and reliable heritage information for not only the dissemination of heritage records, but also for the site's eventual conservation. A wide range of recording and documentation tools resulted in the preparation of a comprehensive heritage record.

The predetermined objectives that were to be obtained from the BIM and structural model were explored as a useful tool in heritage recording and analysis.

The objective that was set for this project was two-fold. The first was to design a Building Information Model (BIM) to be used for multiple applications as an accurate representation for heritage conservation. The second was to provide a better understanding regarding the relationship between an accurate general use BIM model and an analytical model for structural analysis. 
The first objective was effectively met, given that a BIM model with appropriate accuracy of the spatial and physical configuration of the building was produced. The model included accurate characteristics of the opening sizes, layout, and structural composition, which were the results from 3D scan and survey data.

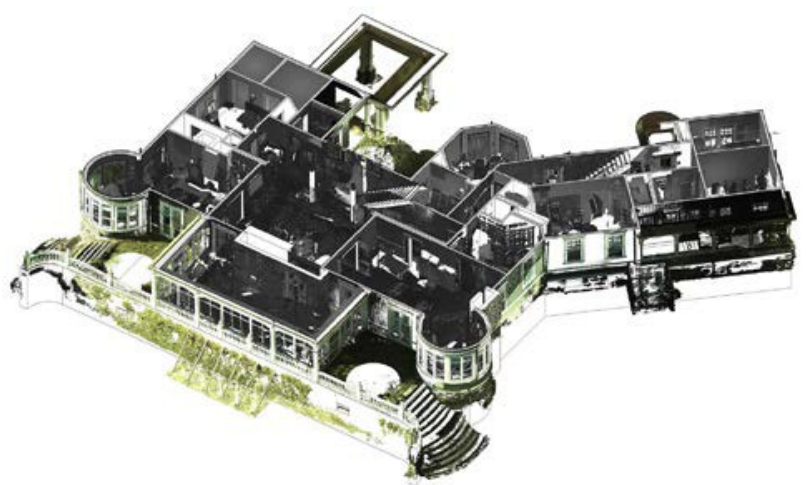

Fig.8 - BIM created from survey and laser scans

The second objective was partially achieved as the results of the structural analysis did not yield usable (or relevant) analytical results. However, the team was able to develop a protocol for the use of heritage building documentation information gathered by 3D scanning to construct a structural analytical model in Revit, but the structural load and material details require further work. One of the notable aspects of the method was that it allowed visually and metrically capture the sag of the structure, however the goal to accurately measure it analytically requires further investigation.

\section{RECOMMENDATIONS}

The project team believes that further research is required in the development of parametric modelling tools to improve the correct and accurate representation of the true character defining element's shapes and geometries in Building Information Models (BIM) packages.

Furthermore, revision of parameters of BIM models of existing buildings will offer more applicable building performance and structural integrity tools.

It is recommended that the records resulting from this activity should be kept in a central repository and managed, enabling a good longevity approach, as to consider contributing the records to existing digital libraries initiatives to ensure transfer (and eventual update) of this information, such as the library of Congress HABS collection.

Finally, a holistic approach, centered on the relevance of information to understand the significance, integrity and threats to our heritage is of paramount importance. Heritage value is a crucial concept in defining the extent and effective capturing and disseminating knowledge of heritage places.

\section{ACKNOWLEDGEMENTS}

The authors wish to acknowledge and thank the support of Mitacs Accelerate program, Sara Grosvenor, the trustees of Beinn Bhreagh Hall and the Bell family for this unique opportunity to collaborate in the preservation of this important landmark.

In addition, we wish to thank the support of Carleton Immersive Media Studio (CIMS) staff and staff from Beinn Bhreagh for their support to this project.

We must also acknowledge the hard work and crucial contribution of the faculty members Stephen Fai and William O’Brien, as well as, Aly Abdelalim for the building performance simulation.

Finally, we want to thank all those individuals and institutions that in one way or the other helped with the completion of this report.

\section{REFERENCES}

2nd International Congress of Architects and Technicians of Historic Monuments. "International Charter for the Conservation and restoration of Monuments and Sites (The Venice Charter 1964)." ICOMOS. 1964. http://www.icomos.org/charters/ venice_e.pdf (accessed July 10, 2015).

Böhler, W., and A. Marbs. "3D Scanning Instruments." ISPRS WG6 Scanning for Cultural Heritage. Corfu: The International Archives of the Photogrammetry, Remote Sensing and Spatial Information Sciences, 2002.

English Heritage. "3D Laser Scanning for Heritage." Historic England. 2011. https://content.historicengland.org.uk/imagesbooks/publications/3d-laser-scanningheritage2/3D_Laser_ Scanning_final_low-res.pdf, pp.7-10 (accessed July 14, 2015).

J., McCarthy. "Multi-image photogrammetry as a practical tool for cultural heritage survey and community engagement." JOURNAL OF ARCHAEOLOGICAL SCIENCE, 2014: 175-85.

"Leica ScanStation C10 DS" Leica Geosystems. 2011. http://hds.leica-geosystems.com/downloads123/hds/hds/

ScanStation\%20C10/brochures-datasheet/Leica_ScanStation_ C10_DS_en.pdf (accessed July 14, 2015).

"Leica Viva TS11 DS" Leica Geosystems. 2010. http://www.leica-geosystems.com/downloads123/zz/tps/Viva\% 20TS15/brochures-datasheet/Leica\%20Viva\%20TS11\% 20Datasheet_en.pdf (accessed July 14, 2015).

Nikon. 2014. http://imaging.nikon.com/lineup/dslr/ d800/spec.htm (accessed July 14, 2015).

Parks Canada. "Standards and guidelines for the conservation of historic places in Canada: a federal, provincial and territorial collaboration." Canada's Historic Places. 2010. http://epe.lacbac.gc.ca/100/200/301/parkscanada/standards_and_guidelinese/R62-343-2010-eng.pdf (accessed July 14, 2015).

Phantom 2 Vision Specs. 2015. http://www.dji.com/product/ phantom-2-vision/spec (accessed July 14, 2015).

Watt, David. Surveying historic buildings. 2nd rev. Shaftsbury, Dorset;Kimball, MI: Donhead Pub., 2010, pp.1-3.

Wolf, Paul R, Bon A Dewitt, and Benjamin E Wilkinson. Elements of Photogrammetry with Application in GIS. New York; London: McGraw-Hill, 2014. 